Article

\title{
Precision Farming in Hilly Areas: The Use of Network RTK in GNSS Technology
}

\author{
Alvaro Marucci, Andrea Colantoni, Ilaria Zambon * (iD and Gianluca Egidi \\ Department of Agricultural and Forestry Sciences (DAFNE), University of Tuscia, Via S. Camillo de Lellis, \\ 01100 Viterbo, Italy; marucci@unitus.it (A.M.); colantoni@unitus.it (A.C.); egidi.gianluca@yahoo.it (G.E.) \\ * Correspondence: ilaria.zambon@unitus.it; Tel.: +39-0761357356 \\ Academic Editor: Les Copeland \\ Received: 21 June 2017; Accepted: 19 July 2017; Published: 20 July 2017
}

\begin{abstract}
The number of GNSS satellites has greatly increased over the last few decades, which has led to increased interest in developing self-propelled vehicles. Even agricultural vehicles have a great potential for use of these systems. In fact, it is possible to improve the efficiency of machining in terms of their uniformity, reduction of fertilizers, pesticides, etc. with the aim of (i) reducing the timeframes of cultivation operations with significant economic benefits and, above all, (ii) decreasing environmental impact. These systems face some perplexity in hilly environments but, with specific devices, it is possible to overcome any signal deficiencies. In hilly areas then, the satellite-based system can also be used to safeguard operators' safety from the risk of rollover. This paper reports the results obtained from a rural development program (RDP) in the Lazio Region 2007/2013 (measure project 1.2.4) for the introduction and diffusion of GNSS satellites systems in hilly areas.
\end{abstract}

Keywords: precision farming; hilly areas; Network RTK; GNSS technology

\section{Introduction}

Precision agriculture has provided a remarkable positive contribution to the primary sector globally at various levels [1-4]. Unlike conventional agricultural methods, it can adapt crop yields by considering the local variability of the physical, chemical, and biological characteristics of soils, as well as the application time through the development of technological and computer support [5-7]. Precision agriculture employs machines equipped with "intelligent systems", which can measure production factors in relation to the real needs of a plot and of different homogeneous areas within it [8]. According to [9], several goals can be achieved, such as: (i) enhancing yields with the same total inputs; (ii) reducing inputs with equal yield; (iii) increasing yields by reducing inputs at the same time. Furthermore, when applied to conservative soil methods, the principles of precision agriculture can (i) maintain environmental benefits, (ii) improve corporate income, and (iii) rationalize the use of machines [10,11].

Analyzing precision farming from environmental, economic, and management points of view, several positive impacts emerge, which should not be underestimated [10,12-14]. Focusing on economic benefits, an overall optimization of crop interventions can be detected, together with a quantitative reduction of distributed chemicals [13] and an improved operational and safety capacity for operators in their workplace. It should also be stressed that the above-mentioned economic benefits can also be derived from two reasons: firstly, for the probable growth in costs of the production factors; secondly, on the other hand, for the likely reduction in the cost of purchasing technical equipment, which occurs as demand and technological evolution rise.

The modern approach to precision agriculture is based on flexible customized and equipped technology solutions with extensive interoperability. This method is essential as it is able to manage 
the wide variability of usage conditions in typical Italian farms, which are characterized by their (often highly fragmented) land capital [15-19]. The diffusion of highly-innovative techniques, favored by their adaptability to each agricultural reality, would substantially contribute to the modern transformation of productive processes in the Italian primary sector [20]. Nowadays, the use of a service platform for product data capture related to production is widely available in several areas through local devices. The latter include sensors, automatic guidance systems with Global Navigation Satellite Systems (GNSS), and central processing systems. Specifically, GNSS technology, as a European global navigation satellite system, ensures greater positioning accuracy and reliability compared to GPS, as it is designed to provide real-time positioning services [21-23]. The use of the signals of GNSS was initially anticipated in the late 1980s $[24,25]$ and experimentally confirmed in the early 1990s [26]. Regardless of this initial approach to GNSS techniques, the initial efforts to evaluate soil moisture from reflectivity dimensions arise in 2003 [27]. GNSS, such as the Global Positioning System (GPS) technology, has grown and developed as a controlling atmospheric remote sensing tool able to provide precise observations of atmospheric parameters. The success of GPS has stimulated additional progress of GNSS technology. Nevertheless, these two systems can be defined as complementary [28]. An additional value of these kind of technologies is that they can perform in all weather conditions. This feature of GNSS offers useful information also during cloudy and rainy days, which are still uncertain blocks to radar systems and low Earth orbiting satellites [29].

Potential technical enhancements must be set in the background of processing power and sophisticated technology previously incorporated into GPS receivers [13]. These devices (as GNSS technology) permit land mapping. Through the latter, a geo-referenced data survey, allows observation of the characteristics of the field to be cultivated (e.g., size and perimeter) and defines subsequent planning phases. An information flux between rural machines and the farm's management can be performed. In this way, through these devices, it is possible to optimize automation with vehicles, which can repeat (or exclude) a path already done. Lastly, an appropriate technical analysis points out (i) the enhancement points and agronomic practices to be implemented or, simply, (ii) a unique business database reporting the surfaces of the cultivated areas and the activities carried out on them.

GNSS technologies can rapidly get involved when critical events emerge due to a specific incident or agent. This smart advice could a save of products and reduce environmental impact, without (i) having to maximize the use of technical vehicles (e.g., seeds and fertilizers) and (ii) taking account of the tangible need for crops or the (qualitative and quantitative) presence of weeds. Even if these techniques are mainly spreading in flat areas, increasing attention to site-specific management in precision farming is emerging in hilly contexts [30]. In the latter areas, precision agriculture continues to be very limited due to the effort required during the assessment. Hills can be a relevant cause for missing observations [31]. One of their main limits is the highest error probability, even where hills are small, compared to the flatter regions [23,32].

The positioning system (as GPS) can continuously record both the in-field and the correct position of a vehicle in use [33]. All the collected data can then be processed through a Geographic Information System program (GIS). The latter can produce valid agro-technological assessments and multifaceted examinations of rural fields [34].

Measuring the effective distribution of such systems in less-favored areas, a project was carried out under the rural development program (RDP) in the Lazio Region 2007/2013 measure 1.2.4. The latter aims to assess financial farming conditions. European support might be granting merely the supplementary financing needed to implement the project in more attractive farms (in terms of local sources or banking system) [35].

The experimental activities envisaged in the project concerned:

- the employment of a permanent station network (Network RTK), exportable as a connection model to other users, (i) improving the efficiency of applications in precision agriculture and (ii) exporting processing data in the areas (to be tested) in a corporate GIS program; 
- the execution of experimental assessments on defined areas, evaluating how to reduce the use of technical vehicles in three different ways of driving (manual, assisted, automatic);

- the identification of areas with special orographic constraints, using the GIS program, sending warnings to operators both at entry and exit from the area, and even in cases of excessive inclination of the vehicle during its use (avoiding potential risk of overturning).

\section{Materials and Methods}

For the execution of experimental tests (at the stage of weeding), three farms have been identified. Achieving the main purpose of this work, a homogeneous environment was chosen for the selected farms, where only one seasonal crop was present (wheat). The three farms are representative of the agricultural reality in Tuscia. The territory of Tuscia is an area that often coincides with the province of Viterbo, located in the central part of Italy. The satellite-navigation systems have been installed on all the vehicles of the selected farms, including an electric steering wheel (Figure 1), control monitor, and GNSS antenna (Figure 2).

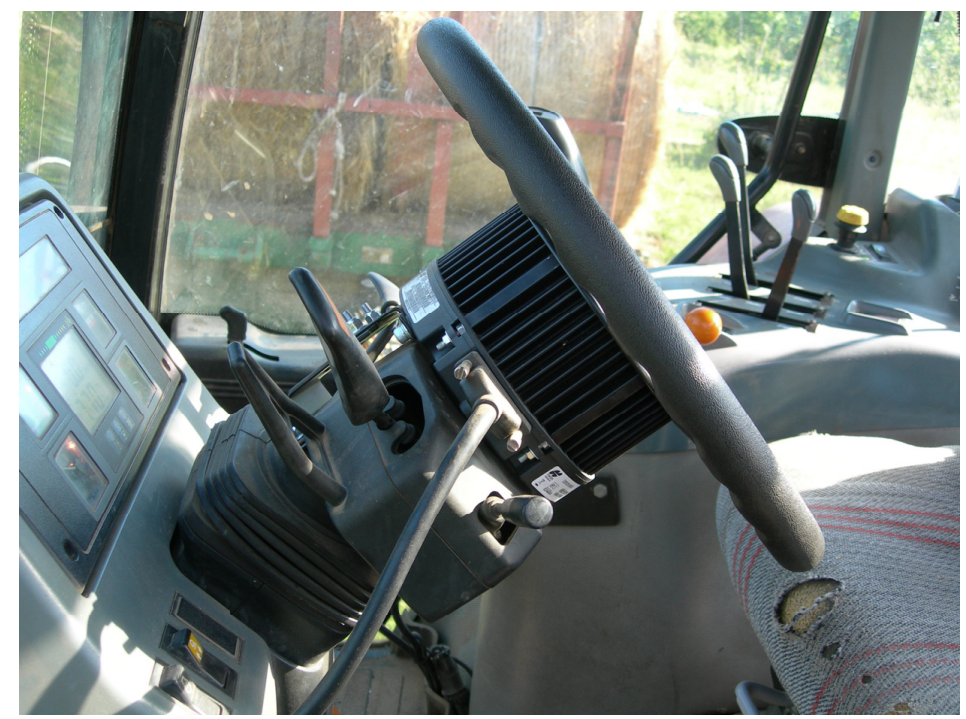

Figure 1. Steering wheel with automatic guidance device.

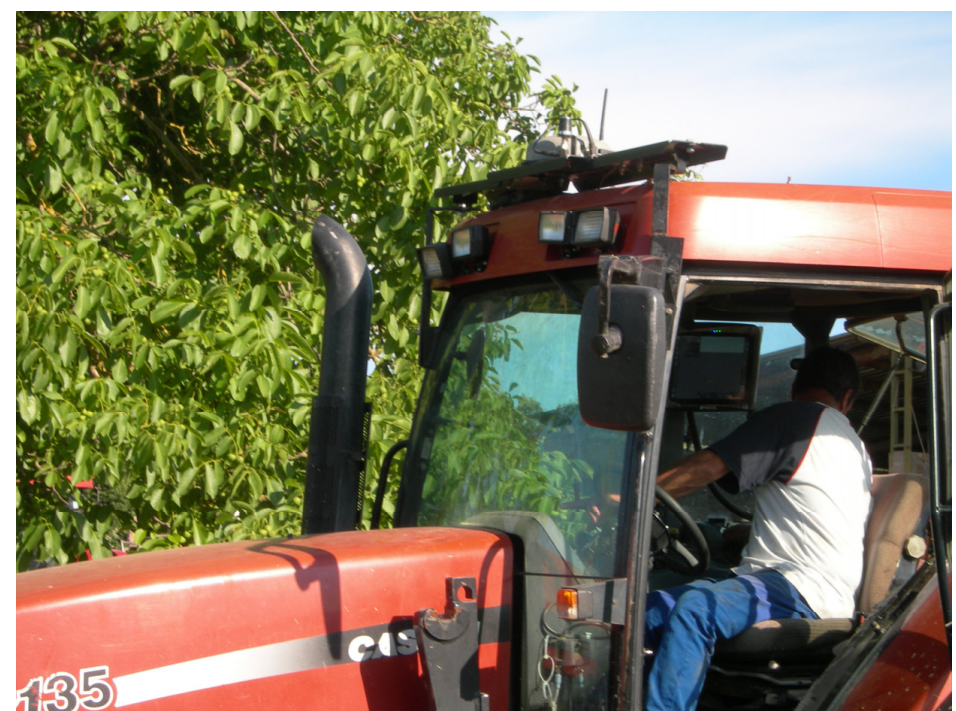

Figure 2. Monitor and antenna installed on the tractor. 
In these instruments, calibrations were performed for automatic guidance and configuration for the network connection of permanent RTK stations.

The network of permanent RTK stationary stations was developed for the distribution of differential corrections for geodesy and topography, enable the performance topographic surveys with only one receiver connected to one of the available networks.

This technology and methodology, if used even in precision agriculture applications, can: (i) avoid installing and using the "base", where it is possible to operate with only one receiver on the vehicle; (ii) operate across the area covered by the network and border areas, without having the problem of distance from the reference station, always with the same position precision; (iii) gain greater system reliability and integrity, due to the systematic error management resulting from the overall network calculation; (iv) dispel all doubt and ambiguity compared to the traditional RTK technique; (v) know the spatial position of the vehicle in a single and controlled reference system; (vi) have a high degree of repeatability, over time, both of the positioning and operation of the vehicle; (vii) receive distribution across the internet (NTRIP protocol) of differential corrections; and (viii) operate in areas with low GPRS/UMTS coverage through local solutions (RTK Bridge).

Differential correction occurs via the Virtual Reference Station (VRS), whose operating principles are:

- the receiver on the agricultural vehicle estimates its approximate location (error of a few meters) through the GPS and GLONASS satellites only and sends it to the control center thanks to the active connection of its modem;

- the control center generates a dedicated (virtual) base station for the potential user and sends differential corrections in real time;

- the receiver on the agricultural vehicle corrects its estimated position with the data sent by the network and achieves a centimeter accuracy.

The subsequent experimental activity concerned the evaluation of reducing the number of technical vehicles employed. Such activity, envisaged for an entire crop cycle, was addressed to every single agronomic practice from soil preparation up to harvesting.

The test area extends over as surface of approximately three hectares, divided into three equal portions, following their physical and geo-morphological characteristics. By way of example, the results in the next paragraph are related to the weeding operation. This choice is surely one of the most beneficial activities from satellite navigation systems.

The transaction data was recorded and downloaded from the system for consequent analysis. The execution times for each individual processing have been scheduled, by tracking the consumption of the product used and verifying the correct functioning of the satellite system in the intended modes of use. During the tests, three driving systems were verified: manual, assistive, and automatic.

In the first mode, cultivation operations were carried out by an operator without any technological aid. In this case, the system recorded only the path of the machine and other technical data (e.g., position, time, feed rate, path).

In the second mode, the same operations were carried out using the assisted guidance GNSS system. In this situation, the operator was facilitated more by the onboard computer system. The latter reported the path and the deviation from the trajectory to be followed in a monitor/video.

The third mode involved the implementation of a total automation processes. The tractor followed specific paths, defined on a map, through the automatic pilot. The operator was limited to monitoring the correct operation of devices and operating machines. This compares the traditional operating modes with precision agriculture, in terms of products used, execution times, and job safety. The reduction of environmental emissions into the atmosphere and the inadequacies in the implementation of agronomic practices were also assessed.

Regarding the latest research goal, a fleet management device was not immediately visible from the cabin (as it is an alarm device in case of theft). The system has many configuration options and functions, as well as serving as an aid to the management and maintenance of the vehicle itself. It is also 
possible to define a "limit zone" in the system: if the vehicle exits or enters this area, at uninterrupted time intervals, even when the engine is off, the device sends SMS or e-mail alerts.

For areas with poor Internet coverage, a device called an RTK-Bridge has been tested (Figure 3).

The device was placed in an area where there was a low Internet coverage. It has been connected to the permanent station network, sending its approximate position. It downloaded the differential corrections and then redistributed all the media operating through a low power radio. The width of the radio coverage depends on the territorial profile and the presence of obstacles. Like all radio devices, it is better to place the device at the highest point of the working area. In addition, for increasing operator safety, a device has been tested to send alarms via SMS and to switch on an led in the cabin, when one or more previously set inclination values of the vehicle have been reached. Two limit corners were set (a first angle of $15^{\circ}$ and a second one of $45^{\circ}$ ). This latter angle greatly exceeded the safety limits for crawler tractors, and thus represented an alarm for probable overturning of the vehicle.

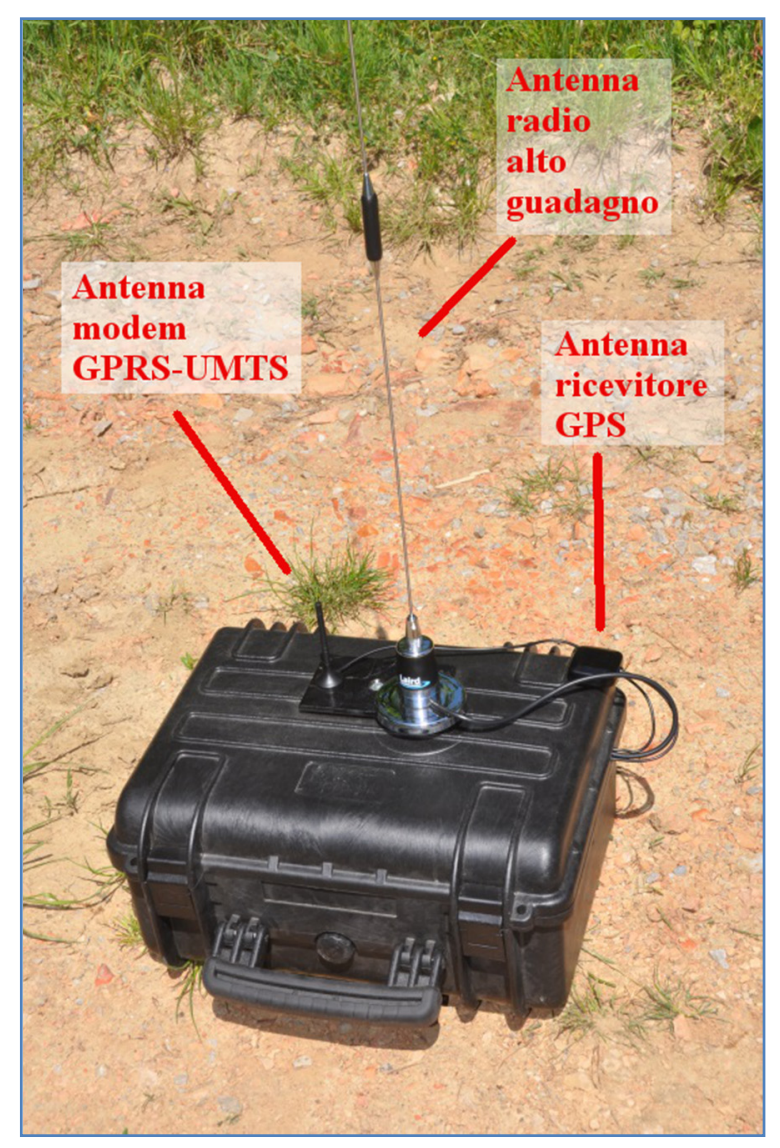

Figure 3. RTK-Bridge device.

\section{Results}

The experimentation for the use of permanent stations in precision agriculture has achieved several significant results. It showed that (i) the correction sent by permanent stations via the Network RTK to the GNSS system, concerning the vehicle in motion, was uniform and then (ii) the degree of precision varied with respect to the satellite constellation, visible during use and according to GPRS coverage, with which the system connected firstly to the network and then to the server. The system has changed, passing from "FIXED" (the system is connected to the network and receives a centimeter-accurate correction) to "FLOAT" (connected to the network but receiving a sub-metric precision correction) or to "STD" (the system is not connected to the network and collects only satellite correction with metric accuracy). However, the system can maintain the predetermined trajectory of 
the agricultural vehicle for a few seconds and then it emits a warning alert due to the loss of centimeter accuracy. This allowed us to assess whether the loss of precision was owed to a reduced GPRS signal or to an insufficient satellite constellation. Therefore, it is possible to act accordingly. It is necessary to wait (i) for the satellite signal, which allows a calculation and correction with the "FIXED" solution, or (ii) for the automatic system reconnection to the server. In addition, all data concerning the work carried out from the selected representative farms has been performed in the GIS program. A map about the treated terrains for each individual processing can be achieved. The resulting map quantifies the size of the operational surface areas for subsequent treatment scheduling. This management method allowed a seasonal check of the tasks that need to be performed and a planning of crop operations based on business choices achieved with the help of the GIS system.

Considering the three driving methods (manual, assisted, and automatic), experimental examinations on test areas checked the incidence of the human factor in the management of normal agronomic practices. Several benefits derived from new technologies, optimizing production and ensuring decreases in production times, environmental impacts, and fuel consumption.

The comparison between traditional operating methods and those tested with precision agriculture revealed significant progress, comparing the three driving methods.

In Figure 4, the steps of the agricultural vehicle during the action of weeding are shown (bar $12 \mathrm{~m}$ ). The GNSS system graphically represented the positioning of satellite acquisitions along the path followed by the tractor. The assisted and automatic guidance systems allowed a more homogeneous soil treatment compared to the manual one. The covered surface was much more homogeneous, with the almost total disappearance of untreated areas and overlapping areas. All this is accompanied by a high driving comfort and better ease of execution during the operational activities.

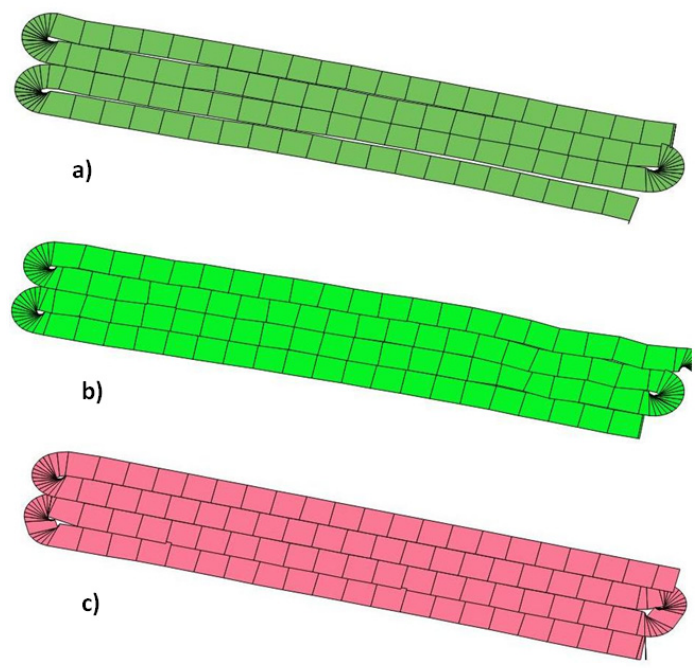

Figure 4. Operation crop weed control: GIS display in manual (a), assisted (b), and automatic guide (c).

The data for the activities carried out during the experimental field tests are shown in the Table 1. The cultivation operations concerned: (i) the soil preparation by $30-35 \mathrm{~cm}$ deep plowing carried out at the end of August without the GNSS system; (ii) fertilization, assuming GNSS aid; (iii) harrowing for the preparation of the sowing bed carried out in mid-November, without the GNSS system; (iv) sowing, following harrowing, with a seed density of about $300 \mathrm{~kg} / \mathrm{ha}$, without the GNSS system; (v) phytosanitary treatment, with chemical and fungicide weeding in mid-January; (vi) chemical weed control (ARIANE + AXIAL + activator) in February-March; (vii) chemical and fungicidal fertilization in April; collection of the product, with a grain yield of about $6 \mathrm{t} / \mathrm{ha}$ and $3.6 \mathrm{t} / \mathrm{ha}$ of straw, at the end of June-July, without the GNSS system. 
Table 1. Primary data collected during experimental field trials.

\begin{tabular}{|c|c|c|c|c|c|}
\hline \multirow{6}{*}{ Primary data } & Type of Crop: Wheat & & & & \\
\hline & & & \multicolumn{3}{|c|}{ Modality } \\
\hline & & & Manual & \multirow{2}{*}{$\begin{array}{c}\text { Assisted } \\
257\end{array}$} & \multirow{2}{*}{$\frac{\text { Automatic }}{254}$} \\
\hline & Seeding density & $\mathrm{kg} / \mathrm{ha}$ & 300 & & \\
\hline & Grain yields & t/ha & 6 & 5.1 & 5.1 \\
\hline & Quantity yield straw & t/ha & 3.6 & 3.1 & 3.1 \\
\hline \multirow{13}{*}{$\begin{array}{l}\text { Cultivation } \\
\text { operations }\end{array}$} & Plowing $(30-35 \mathrm{~cm})$ & \multicolumn{4}{|c|}{ August/September } \\
\hline & $\begin{array}{l}\text { Fertilization before } \\
\text { sowing }\end{array}$ & $\begin{array}{l}\text { Panfertil (Phosphate } \\
\text { Biammonics 18-46) } \\
\text { Dose: kg/ha }\end{array}$ & 250 & 214 & 212 \\
\hline & Harrowing & \multicolumn{4}{|c|}{ November } \\
\hline & Sowing & \multicolumn{4}{|c|}{ November } \\
\hline & $\begin{array}{l}\text { Chemical fertilization } \\
\text { in January }\end{array}$ & $\begin{array}{c}\text { Panfertil (Phosphate } \\
\text { Biammonics 18-46) } \\
\text { Dose: kg/ha }\end{array}$ & 200 & 171 & 170 \\
\hline & \multirow{2}{*}{$\begin{array}{l}\text { Chemical disinfection } \\
+ \text { fungicide in January }\end{array}$} & GLEEN (kg/ha) & 0.030 & 0.026 & 0.025 \\
\hline & & $\begin{array}{l}\text { Fungicida Zantara } \\
\text { (Bayer) }(1 / \text { ha) }\end{array}$ & 1.5 & 1.28 & 1.27 \\
\hline & \multirow{3}{*}{$\begin{array}{l}\text { Chemical disinfection } \\
\text { in February/March }\end{array}$} & $\begin{array}{l}\text { ARIANE for wide leaf } \\
(1 / \text { ha })\end{array}$ & 3 & 2.6 & 2.5 \\
\hline & & $\begin{array}{l}\text { AXIAL for little leaf } \\
(1 / \mathrm{ha})\end{array}$ & 1 & 0.86 & 0.85 \\
\hline & & Activator (l/ha) & 1 & 0.86 & 0.85 \\
\hline & \multirow{2}{*}{$\begin{array}{l}\text { Fungicidal chemical } \\
\text { fertilization in April }\end{array}$} & AMIDAS urea $(\mathrm{kg} / \mathrm{ha})$ & 200 & 171 & 170 \\
\hline & & $\begin{array}{l}\text { Fungicida Zantara } \\
\text { (Bayer) }(1 / \text { ha })\end{array}$ & 1.5 & 1.28 & 1.27 \\
\hline & Collection period & June/July & & & \\
\hline
\end{tabular}

In addition to a much better uniformity of treatment, significant reductions of products used should also be noted over time. Table 2 reports the different parameters chosen: time spent during the operations (expressed in minutes); product used, i.e., products which are used during the operations of weeding (expressed in liters); rural surface area (expressed in hectares); and distance travelled, otherwise the length of the path carried out by the vehicle (expressed in kilometers). The parameters were then detected according to the three-driving controls observed in the present work. With the same coverage area and distance travelled, the time employed and the amount of product used were considerably reduced in assisted and automatic guidance compared to manual driving. More specifically, time duration was reduced by $3.30 \%$ and the product used by $14.37 \%$ in assisted driving (when respectively they are $6.13 \%$ and $15 \%$ in automatic guidance). This result revealed that the transition from the assisted driving to the automatic mode did not affect the product used. For example, the overlapping or non-treated areas are almost non-existent in both modes. Instead, concerning the time spent, the automatic driving mode can be substantially preferred. The field tests carried out immediately provided divergent results, based on the parameters and the three driving types considered. For this reason, the data collected has not been combined even with statistical techniques. 
Table 2. Comparison of the parameters found in the three types of soil processing.

\begin{tabular}{cccccc}
\hline Parameters Signed & Manual Guide & \multicolumn{2}{c}{ Assisted Guide } & \multicolumn{2}{c}{ Automatic Guide } \\
\hline Time spent (min) & $7: 04$ & $6: 50$ & $-3.30 \%$ & $6: 38$ & $-6.13 \%$ \\
Product used (l) & 355 & 304 & $-14.37 \%$ & 301 & $-15.21 \%$ \\
Surface area (ha) & 1.25 & 1.25 & - & 1.25 & - \\
Distance travelled $(\mathrm{km})$ & 1.10 & 1.10 & - & 1.10 & - \\
\hline
\end{tabular}

Lastly, the introduction and installation of a telematic control system in common farms enabled the monitoring of their work and the performance of their vehicles. This can prevent risks in terms of unauthorized use of material goods, thefts, unplanned work, and unexpected movements. Above all, telematic control systems can constantly monitor the job conditions of workers, avoiding hazardous situations inside the passenger compartment on the agricultural vehicle.

The test performed confirmed the correct operation of the device installed in all its operating modes. Utilizing this method of monitoring and controlling agricultural operations, any type of operational risk can be avoided, from theft and damage of agricultural resources, to greater dangers-without excluding the overturning of agricultural vehicles—with the possibility of saving human lives.

\section{Discussion}

Despite an increasing awareness in hilly situations [30,36], techniques for precision farming are essentially used in flat areas. One of the major problems of precision agriculture concerns the difficulty of properly monitoring and managing hilly areas due to the high probability of error and loss of important information during detection operations [23,31,32]. This trouble can become critical if precision agriculture is applied to the Italian context. The latter presents a very varied territory, in which there is a strong presence of hillsides. Moreover, Italy has a fragmented rural landscape [20], which may complicate territorial analysis operations. Few studies have focused and compared GPS and GNSS technologies, demonstrating their validity in hilly areas [37].

In this paper, attempts have been made to minimize possible errors derived from GNSS technology. Devices as GNSS technology permit land mapping, optimizing machining operations in which rural vehicles can repeat (or exclude) a path already done. The innovative element of GNSS technology is the opportunity of putting rural machines and the farm management in communication. This interaction allows a timely technical analysis that points out the degree of improvement, further agronomic practices that need to be implemented, or a unique business database containing all the surface areas cultivated and the activities carried out on them. All the collected data can be processed through a Geographic Information System program (GIS), allowing rural processes and suitable agro-technological assessments [34]. GIS and remote sensing are layer-based systems, giving their users the flexibility to superimpose different levels of reality and find the best model for more accurate agricultural practice. An interpolated map describing the soil type, slope, and aspect in hilly areas can simulate the yield of crops with various variety groups and other agricultural inputs. With specific devices (RTK bridge), it is possible to overcome any signal deficiencies. Finally, in rugged hilly terrain areas, using the satellite navigation system can safeguard operators' safety from potential risk concerning the overturning of agricultural vehicles.

The present work gives new insights for research activities in hilly environments. In fact, with simple field trials at the stage of weeding, significant results have been achieved, without requiring statistical comparison. Achieving the main purpose, a homogeneous environment was chosen for the selected farms, where only one seasonal crop was present (wheat). Future research development may deal with heterogeneous environments having different crop areas and more than one crop season cycle. 


\section{Conclusions}

Based on the results obtained with a RDP in the Lazio Region 2007/2013 measure 1.2.4, this paper reveals the actual possibilities of utilizing satellite guidance systems for agricultural vehicles in hilly areas, which are certainly less optimal than areas with more regular orography. The results obtained showed suitable possibilities of using these systems even in hilly environments. Therefore, the research topic proposed in this paper gives innovative insights, especially for researchers and even for farm producers. Considerable benefits have been achieved in terms of uniformity of machining, potential reduction of (chemical) products used, and operator safety during the working time.

Acknowledgments: Research carried out under the RDP Project Measure 124 entitled “Introduction of Sustainable Processes and Methods using RTK Satellite Technologies and Corporate GIS for the Development of Precision Agriculture in Tuscia" financed by the Lazio Region with a measure of concession of aids n. 31/124/10 of December 12th, 2014; Public Notice DGR n.76/2014 and s.m.i.

Author Contributions: Alvaro Marucci performed the experiments, analyzed the data, and contributed materials and tools; Andrea Colantoni designed the experiments; Ilaria Zambon and Gianluca Egidi wrote the paper; Ilaria Zambon was involved in the critical review of the results obtained.

Conflicts of Interest: The authors declare no conflict of interest.

\section{References}

1. Zhang, N.; Wang, M.; Wang, N. Precision agriculture-A worldwide review. Comput. Electron. Agric. 2002, 36, 113-132. [CrossRef]

2. Florax, R.J.G.M.; Voortman, R.L.; Brouwer, J. Spatial dimensions of precision agriculture: A spatial econometric analysis of millet yield on Sahelian coversands. Agric. Econ. 2002, 27, 425-443. [CrossRef]

3. McBratney, A.; Whelan, B.; Ancev, T.; Bouma, J. Future directions of precision agriculture. Precis. Agric. 2005, 6, 7-23. [CrossRef]

4. Pretty, J.; Sutherland, W.J.; Ashby, J.; Auburn, J.; Baulcombe, D.; Bell, M.; Campbell, H. The top 100 questions of importance to the future of global agriculture. Int. J. Agric. Sustain. 2010, 8, 219-236. [CrossRef]

5. Berti, A.; Zanin, G. Density Equivalent: A method for forecasting yield losses caused by mixed weed populations. Weed Res. 1994, 34, 326-332. [CrossRef]

6. Berti, A.; Borin, M.; Giupponi, C.; Morari, F.; Zanin, G.; Duso, C.; Furlan, L.; Rizzo, S.; Sartori, L.; Nardi, S.; et al. Potenzialità Applicative dell'agricoltura di Precisione Nell'ambiente Veneto; Veneto Agricultura: Milano, Italy, 2000.

7. Pierce, F.J.; Sadler, E.J. The State of Site Specific Management for Agriculture; ASA Publ.: Madison, WI, USA, 1997.

8. Verhagen, J.; Bouma, J. Modeling soil variability. In The State of Site Specific Management for Agriculture; Pierce, F.J., Sadler, E.J., Eds.; ASA Publ.: Madison, WI, USA, 1997.

9. Robert, P.C. Characterisation of soil conditions at the field level for soil specific management. Geoderma 1993, 60, 57-72. [CrossRef]

10. Bongiovanni, R.; Lowenberg-DeBoer, J. Precision agriculture and sustainability. Precis. Agric. 2004, 5, 359-387. [CrossRef]

11. Adamchuk, V.I.; Hummel, J.W.; Morgan, M.T.; Upadhyaya, S.K. On-the-go soil sensors for precision agriculture. Comput. Electron. Agric. 2004, 44, 71-91. [CrossRef]

12. Auernhammer, H. Precision farming-The environmental challenge. Comput. Electron. Agric. 2001, 30, 31-43. [CrossRef]

13. Stafford, J.V. Implementing precision agriculture in the 21st century. J. Agric. Eng. Res. 2000, 76, $267-275$. [CrossRef]

14. Oliver, M.; Bishop, T.; Marchant, B. Precision Agriculture for Sustainability and Environmental Protection; Routledge: London, UK, 2013.

15. Lund, P.J.; Hill, P.G. Farm size, efficiency and economies of size. J. Agric. Econ. 1979, 30, 145-158. [CrossRef]

16. Van Dijk, T. Scenarios of Central European land fragmentation. Land Use Policy 2003, 20, 149-158. [CrossRef]

17. Alvarez, A.; Arias, C. Technical efficiency and farm size: A conditional analysis. Agric. Econ. 2004, 30, 241-250. [CrossRef] 
18. Gorton, M.; Davidova, S. Farm productivity and efficiency in the CEE applicant countries: A synthesis of results. Agric. Econ. 2004, 30, 1-16. [CrossRef]

19. Galluzzo, N. Technical and economic efficiency analysis on Italian smallholder family farms using Farm Accountancy Data Network dataset. Stud. Agric. Econ. 2015, 117, 35-42. [CrossRef]

20. Pisante, M.; Stagnari, F.; Grant, C.A. Agricultural innovations for sustainable crop production intensification. Ital. J. Agron. 2012, 7, 40. [CrossRef]

21. Spiller, J.; Tapsell, A.; Peckham, R. Planning of future satellite navigation systems. J. Navig. 1999, 52, 47-59. [CrossRef]

22. Divis, D.A. Galileo enthusiasm and money propel Europe's GNSS. GPS World 1999, 10, 12-16.

23. Crespi, M.; Mazzoni, A.; Brunini, C. Assisted Code Point Positioning at Sub-meter Accuracy Level with Ionospheric Corrections Estimated in a Local GNSS Permanent Network. In Geodesy for Planet; Springer: Berlin, Germany, 2012.

24. Sánchez, N.; Alonso-Arroyo, A.; González-Zamora, A.; Martínez-Fernández, J.; Camps, A.; Vall-1losera, M.; Pablos, M.; Herrero-Jiménez, C.M. Airborne GNSS-R, thermal and optical data relationships for soil moisture retrievals. In Proceedings of the Geoscience and Remote Sensing Symposium (IGARSS), Milan, Italy, 26-31 July 2015; pp. 4785-4788.

25. Hall, C.D.; Cordey, R.A. Multistatic Scatterometry. In Proceedings of the IEEE International Geoscience and Remote Sensing Symposium, IGARSS, Edinburgh, UK, 12-16 September 1988; Volume 1, pp. 561-562.

26. Auber, J.-C.; Bibaut, A.; Rigal, J.-M. Characterization of Multipath on Land and Sea at GPS Frequencies. In Proceedings of the 7th International Technical Meeting of the Satellite Division of The Institute of Navigation (ION GPS 1994), Salt Lake City, UT, USA, 20-23 September 1994; pp. 1155-1171.

27. Zavorotny, V.U.; Masters, D.; Gasiewski, A.; Bartram, B.; Katzberg, S.; Axelrad, P.; Zamora, R. Seasonal polarimetric measurements of soil moisture using tower-based GPS bistatic radar. In Proceedings of the IEEE International Geoscience and Remote Sensing Symposium, IGARSS, Toulouse, France, 21-25 July 2003; pp. 781-783.

28. Choy, S.; Fu, F.; Dawson, J.; Jia, M.; Kuleshov, Y.; Chane-Ming, F.; Chuan-Sheng, K.; Yeh, T.K. Application of GNSS Atmospheric Sounding for Climate Studies in the Australian Region. In Proceedings of the FIG Working Week, Sofia, Bulgaria, 17-21 May 2015; pp. 1-13.

29. Awange, J.L. Environmental Monitoring Using GNSS: Global Navigation Satellite Systems; Springer Science \& Business Media: Berlin, Germany, 2012.

30. Wu, W.; Liu, H.B.; Dai, H.L.; Li, W.; Sun, P.S. The management and planning of citrus orchards at a regional scale with GIS. Precis. Agric. 2011, 12, 44-54. [CrossRef]

31. Brown, N.; Kaloustian, S.; Roeckle, M. Monitoring of open pit mines using combined GNSS satellite receivers and robotic total stations. In Proceedings of the 2007 International Symposium on Rock Slope Stability in Open Pit Mining and Civil Engineering; ACG: Perth, Australia, 2007.

32. Ressl, C.; Pfeifer, N.; Mandlburger, G. Applying 3D affine transformation and least squares matching for airborne laser scanning strips adjustment without GNSS/IMU trajectory data. In Proceedings of the ISPRS workshop laser scanning, Calgary, Canada, 29-31 August 2011; pp. 1682-1777.

33. Neményi, M.; Mesterházi, P.Á.; Pecze, Z.; Stépán, Z. The role of GIS and GPS in precision farming. Comput. Electron. Agric. 2003, 40, 45-55. [CrossRef]

34. Pecze, Z.; Neményi, M.; Mesterházi, P.Á.; Stépán, Z. The function of the geographic information system (GIS) in precision farming. IFAC Proc. Volumes 2001, 34, 15-18. [CrossRef]

35. Dono, G.; Ceccarelli, L. Assessing the financial viability of agricultural investment: Indicators for projects submitted to the PSR (2007-2013) of the Lazio Region. Riv. Econ. Agraria 2010, 65, 465-485.

36. Fu, M.; Zhang, J. Construction Standard of Farmland Landscape Pattern in China Based on Precision Agriculture. In Computer and Computing Technologies in Agriculture II, Volume 1: The Second IFIP International Conference on Computer and Computing Technologies in Agriculture (CCTA2008); Springer: Beijing, China, 2009.

37. Filip, A.; Bazant, L.; Mocek, H.; Cach, J. GPS/GNSS based train position locator for railway signalling. WIT Trans. Built Environ. 2000, 50, 16.

(C) 2017 by the authors. Licensee MDPI, Basel, Switzerland. This article is an open access article distributed under the terms and conditions of the Creative Commons Attribution (CC BY) license (http:// creativecommons.org/licenses/by/4.0/). 